\title{
HET AFAKASCHRIFT IN DE AFRIKANISTIEK
}

The indigenous scripts of West Africa and Surinam; their inspiration and design, door DAviD DALBY, African Language Studies IX, 1968, p. 156-197, 7 tabellen. Uitgegeven voor de School of Oriental and African Studies van de Universiteit van London, door Luzac \& Co Ltd., London.

De in 1968 gepubliceerde omvangrijke en grondig gedocumenteerde studie van Dr. David Dalby, Reader in West African Languages aan de Universiteit van Londen, opent nieuwe perspectieven voor de studie van het Afakaschrift, het autochtone syllabeschrift van de Djoeka's aan de Tapanahonie, doordat het dit onderwerp vanuit het gebied der eigenlijke Surinamistiek brengt naar het groter terrein van de inheemse Westafrikaanse schriftsoorten.

In 1967 verscheen van dezelfde schrijver: 'A survey of the indigenous scripts of Liberia and Sierra Leone: Vai, Mende, Loma, Kpelle and Bassa' (African Language Studies VII, I967, p. I-5I). Hierin werden vijf Westafrikaanse schriftsoorten besproken; vier ervan syllabeschriften. Opvallend was reeds in deze studie het grote aantal overeenkomsten - vooral wat de ontstaansgeschiedenis betreft - tussen deze schriften en het Djoekaschrift van Afaka in Suriname. In het Naschrift van C. N. DubelaAR \& J. W. GongGryp's artikel over 'Het Afakaschrift' in dit tijdschrift $(46,1968$, p. $232-260)$, werden deze overeenkomsten reeds vermeld.

DALBY's artikel over 'The indigenous scripts of West Africa and Surinam' is een voortzetting van zijn publicatie van 1967 , waarbij het aantal besproken schriftsoorten uitgebreid is tot tien, waaronder het Afakaschrift, en waarbij de auteur tracht, tot een algemene verklaring voor het ontstaan van deze schriften te komen.

Een chronologisch overzicht geeft het volgende beeld:

\begin{tabular}{|c|c|c|c|c|}
\hline Datering & Schrift & Land & Soort schrift & Aantal tekens \\
\hline$\pm \mathbf{r} 833$ & Vai & Liberia & Syllabisch & 212 \\
\hline \pm 1903 & Bamum & Cameroun & Syllabisch & 510 \\
\hline \pm 1910 & Bagam & Cameroun & Syllabisch & 'several hundred' \\
\hline \pm r9ro & Djoeka & Suriname & Syllabisch & 56 \\
\hline
\end{tabular}


HET AFAKASCHRIFT IN DE AFRIKANISTIEK

295

\begin{tabular}{|c|c|c|c|c|}
\hline \pm 1920 & Bassa & Liberia & Alfabetisch & $\begin{array}{l}30+5 \text { toon- } \\
\text { tekens }\end{array}$ \\
\hline I92I & Mende & Sierra Leone & Syllabisch & I95 \\
\hline \pm 1930 & Oberi-Okaime & Oost-Nigeria & Alfabetisch & $34+$ cijfers \\
\hline \pm 1930 & Loma & Liberia & Syllabisch & 185 \\
\hline$\pm \mathbf{r 9 3 0}$ & Kpelle & Liberia & Syllabisch & 88 \\
\hline I956 & Bete & Ivoorkust & Syllabisch & 401 \\
\hline
\end{tabular}

Het Afakaschrift valt in deze lijst niet alleen op door het feit dat een Zuidamerikaans negerschrift blijkt te passen in een Westafrikaanse periode van schriftenexplosie, maar vooral ook doordat AFAKA erin slaagde, met slechts 56 tekens een bruikbaar systeem te ontwerpen. De hoeveelheid tekens der andere syllabeschriften varieert van 88 tot 510! Dat de bruikbaarheid niet onder dit geringe aantal tekens geleden heeft - eerder het tegendeel - blijkt ons inziens overtuigend uit de gepubliceerde teksten (vooral in: J. W. GongGryp \& C. DubelaAR: 'De geschriften van Afaka in zijn Djoekaschrift', N.W.I.G. 42, p. 2I3-254).

Het Vai-schrift, dat de reeks opent, werd in I833 samengesteld door Momolu Duwala Bukele, stamhoofd in Liberia. Het vond ingang bij zijn stamgenoten, merendeels analfabeten, en ontwikkelde zich in de loop der Ige eeuw. Aangezien normaliserende tendensen ontbraken, ontstonden er verschillende varianten en nieuwe tekens. In Igoo deed Momolu Massaduor, toen leraar aan een missieschool in Robertsport (Cape Mount), later consul van Liberia in Hamburg, een poging tot standaardisering van het schrift. Hij publiceerde een lijst van tekens met hun klankwaarden en deze lijst vormt de basis van het huidige Standard Vai Script (zie: The Standard Vai Script, University of Liberia, Monrovia, I962).

De activiteiten van MASSAQUOI leidden tot een opleving van het Vai; hierdoor geïnspireerd kwamen naburige Westafrikaanse stammen ertoe, eveneens een schrift te ontwerpen. Ze creëerden daarbij eigen tekens, die weinig of geen invloed van het Vaivoorbeeld vertoonden. Hoe echter deze stimulans zijn invloed uit kon strekken tot Zuid-Amerika is een raadsel! Wij moeten wel aannemen dat AFAKA, steunend op Afrikaanse tradities in dezen, zelfstandig tot zijn opmerkelijke prestatie gekomen is.

Wanneer DALBY deze schriftsoorten gaat vergelijken en tot een synthese tracht te komen, stelt hij eerst scherp vast, wat hij onder schrift verstaat en wanneer hij historische of andere relaties tussen schriftsoorten aanneemt. Schrift is volgens hem een lineair systeem van tekens voor het weergeven van spraakklanken 
in de volgorde waarin die geuit worden. Deze omschrijving sluit dus uitdrukkelijk elk schriftsysteem uit dat niet rechtstreeks de spraakklanken weergeeft, dat dus niet alfabetisch of syllabisch is. (Pictografisch schrift, ideografisch schrift, enz.).

Het aannemen van relaties op grond van overeenkomsten tussen twee schriftsoorten is alleen geoorloofd wanneer er bij een bepaald teken zowel klank- als vormovereenkomst is, of wanneer het een kwestie is van betekenis- en vormovereenkomst. Dit laatste geval zal zich echter kunnen voordoen bij tekens die (nog) een sterk pictografisch karakter hebben (bijv. een golflijn als teken voor water); de bewijskracht is dan niet groot. Inderdaad is het uitsluitend afgaan op vormovereenkomst misleidend. $\mathrm{K}$. RATELBAND 'Een boschnegerschrift van Westafrikaanschen oorsprong', W.I.G. 26, I944, p. 193-208) concludeerde daaruit tot een rechtstreekse relatie tussen het Vai-schrift en het Djoekaschrift van Afaka, een conclusie die zowel door Dalby (in het hier besproken artikel, p. I6I) als door DubELAAR \& GoNGGRYP ('Het Afakaschrift', N.W.I.G. 46, I968, p. 248-253) werd bestreden. Een ander voorbeeld van de 'resultaten' waartoe men komen kan als men alleen let op de vorm der tekens, geeft DALBY op blz. I6o als hij vermeldt hoe Kathleen Hau (Bulletin de l'I.F.A.N. 29, 1967, p. I50-I9I) beweert dat het Oberi Okaime rechtstreeks afgeleid is van het Minoïsche Lineair-A!

Ook maakt DALBY een duidelijk verschil tussen het seculair gebruik van het schrift (voornamelijk mededelingen overbrengen) en het magisch gebruik ervan (als middel om hogere machten gunstig te stemmen, onheil te voorkomen, te toveren, de toekomst te voorspellen, enz.), al zijn deze twee gebruikswijzen dikwijls niet te scheiden.

Wij wezen reeds op de opvallende overeenkomsten in de ontstaansgeschiedenis. Ook wanneer DALBY een lijst van overeenkomende kenmerken en omstandigheden van de auteurs der schriften geeft, valt op dat AFAKA geheel in deze groep past, een afstandsverschil van duizenden kilometers ten spijt:

I. De samenstellers der Westafrikaanse schriften waren jong (op de uitvinder van het Bassa-schrift na).

2. Zij hadden een scherp intellect en een rijke verbeelding; ze zagen het nadeel van een illiteraat volk tegenover gemeenschappen met een schrift.

3. Zij traden op in gebieden waar Christelijke zendelingen actief waren of actief geweest waren. 
4. Zij hadden geleerd, een associatie te leggen tussen geopenbaarde godsdienst en een Heilig Boek, niet alleen van het Christendom maar ook van de Islam. (Hoewel de Islam reeds midden Ige eeuw zijn intrede in Suriname deed, is contact tussen Afaka en deze godsdienst echter welhaast uitgesloten).

In het hoofdstuk 'Design of the scripts' stelt DaLBY de vraag: Hoe kwamen de ontwerpers tot hun schrift? Wat betreft de syllabeschriften geldt deze vraag eigenlijk alleen het Vai en het Afakaschrift, omdat het Mende, Loma en Kpelle in navolging van het Vai geconstrueerd zijn en het Bamum en Bete uitgingen van ideogrammen en pictogrammen, gebruikt in een soort rebussen. (Van het Bagam is alleen bekend dat het bestaan heeft). DALBY neemt invloed aan van reeds bestaande schriftsoorten en grafische systemen:

I. Magisch-cryptische tekensystemen en mystieke symbolen, geassocieerd met de Islam en ook in Afrika voorkomend, welke systemen hij sub-Arabisch noemt.

2. Het Arabische schrift zelf, door de Islam ook in Afrika bekend. 3. De pre-Arabische schriften van het Oostelijk en Westelijk Middellandsezeegebied.

4. Inheemse Westafrikaanse grafische symbolen (geen schrifttekens).

Aan de eerste drie mogelijke invloeden wijdt Dalby talrijke pagina's waarin hij met indrukwekkende belezenheid, overstelpend bronmateriaal en scherpzinnige deducties tot bepaalde conclusies komt. Dit gedeelte is echter niet relevant voor het Afakaschrift. Wel het vierde punt. We geven daarom in het kort DALBY's betoog in dit opzicht weer, waarbij men bedenke dat uit de genoemde gebieden het merendeel van de negerbevolking van Suriname afkomstig is.

Er zijn vóór het Vai geen inheemse schriftsoorten in WestAfrika bekend. Wel talrijke grafische symbolen, die onder meer voor communicatiedoeleinden gebruikt worden. De belangrijkste van deze niet-lineaire symboolsystemen zijn: de twee systemen der Bambara in Mali en het Nsibidisysteem in Oost-Nigeria. Veelbetekenend is daarbij het feit dat de Bambara linguistisch verwant zijn aan de Vai-negers (ze behoren met andere stammen tot de Mande-sprekenden) ${ }^{1}$ en dat het Nsibidi thuis-

1) Prof. Dr. J. A. F. Wils te Nijmegen, aan wie een concept van dit artikel ter inzage werd gegeven, merkte hierbij op: "DALBY gebruikt de term Mande sprekenden in de Engelse zin, d.w.z. voor degenen die een 
hoort in het gebied waar het Bagam, Bamum en Oberi-Okaime ontstaan zijn. Ook het Tifinagh-schrift van de Touaregs kan bijgedragen hebben tot de rol van het Mali-gebied als centrum van allerlei grafisch symbolisme. Hiermee hangen ook samen de rotsinscripties van de zuidelijke Sahara, de eigendomsmerken en rijke decoratieve tradities van de ethnische groeperingen in die streek.

$\mathrm{Er}$ is nauwelijks directe invloed van al deze symbolen op het Vai-schrift aanwijsbaar. Maar ze tonen de belangrijke rol aan die grafische symbolen spelen in Mande-sprekende gemeenschappen. De scheppers der inheemse Westafrikaanse schriftsoorten werkten niet vanuit een vacuum maar hadden een lange grafische traditie ter beschikking. Het sterk-gestyleerde karakter van de Vai-, Mende-, Loma- en Bassa-schrifttekens lijkt te wijzen op een langere ontwikkeling dan het geval zou zijn wanneer ze door de diverse uitvinders onafhankelijk van traditionele invloeden zouden zijn samengesteld.

Wat betekent deze visie voor het vraagstuk van het ontstaan van het Afakaschrift?

Dat de Surinaamse bosneger een rijke erfenis van symbolen heeft is zeker. Allereerst wijzen wij op de motieven in de inheemse houtsnijkunst, waarvan de betekenis door verschillende auteurs is uiteengezet; het laatst door F. H. J. MunTSLAG in zijn boekje 'Tembe' (Amsterdam, I966). Vervolgens hebben wij de proeve van 'schrift' van een 'wisiman' (soort priester-wonderdoktertovenaar) uit Paramaribo, in trance geproduceerd en gepubliceerd in Surinam Folk-Lore, (I936, p. 82-83) van M. J. \& F. S. Herskovits. Ook spreken J. Voorhoeve \& H. C. van RenseLAAR in hun artikel 'Messianism and nationalism in Suriname' (Bijdr. Taal-, Land- en Volkenkunde II8, I962, p. I93 vlg.) over 'Tablets' met grafische symbolen "which had however more a sacred than a phonetic significance". Dan wijzen wij op een lendedoek, door dr. G. D. van WENGEN op een studiereis naar Suriname verworven voor het Rijksmuseum voor Volkenkunde te Leiden, welke doek bij wijze van applicatie bezet is met tekens die sterk aan schrifttekens doen denken en enige gelijkenis met

bepaalde 'string of dialects' als taalmedium gebruiken. Het Mande is intussen een zeer rijk gespreide serie van taalvormen; Delafosse, nog steeds dé autoriteit op dit terrein, vestigt daarop nadrukkelijk de aandacht". 


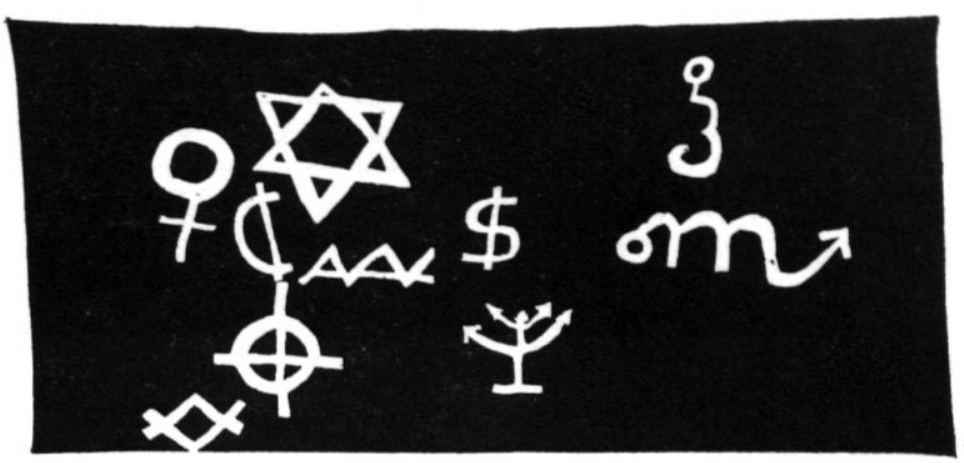

Fig. I. Figuren op een lendedoek van een obia-man uit Paramaribo. [Rijksmuseum voor Volkenkunde, Leiden]

de tekens van het Afakaschrift vertonen (Fig. I). Tenslotte heeft schrijver dezes enkele malen tekens op corjalen en hutten van bosnegers gezien welke de indruk van schrifttekens maken (Fig. 2). Het zal voor hen die kennis gemaakt hebben met de sfeer rondom de religie en magie van de negers, onnodig zijn te vermelden dat in al deze gevallen navraag omtrent de 'betekenis' bij de direct betrokkenen geen resultaat gehad heeft.

Als men in genoemde gevallen invloed van bestaande grafische symbolen op het Afakaschrift zou willen aantonen, komt men niet verder dan enige vage stijlgelijkenis. We hebben hier merkwaardigerwijze dezelfde situatie als in DALBY's artikel: a priori is een dergelijke invloed aan te nemen maar in concreto aantoonbaar is ze nauwelijks. De tabellen waarin hij overeenkomsten in tekenvorm en klankwaarde geeft tussen de schriftsoorten van Liberia/Sierra Leone en het Bamum, Nsibidi, Bambara enz., overtuigen lang niet overal en hij is zich daar blijkens de toelichting zeer goed van bewust.

Suriname kent nog een zesde soort grafische symbolen: de petroglyfen. In hoeverre dit schrifttekens zijn is niet uitgemaakt;

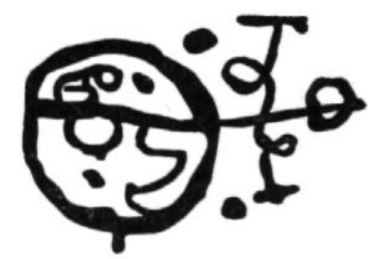

Fig. 2. Figuur op een bosnegerhut in een Djoekadorp aan de Marowijne. 


\begin{tabular}{|c|c|}
\hline ma/mã $\theta$ 'man' & $\begin{array}{l}\text { cf. Vai mo } \\
\text { Mende mo } \circlearrowleft r \text { 'person' }\end{array}$ \\
\hline 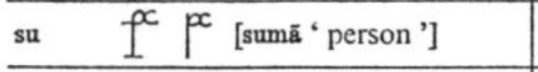 & cf. Bamum mun $\mathcal{Q}$ 'person' \\
\hline ○ & $\begin{array}{l}\text { cf. Djuka } \\
\text { (trad. symbol) }\end{array}$ \\
\hline $\begin{array}{lll}\text { ga } & 9 & \text { [gadu 'God'] } \\
\text { ju } & \mathfrak{Q}_{k} & \text { [juju 'spirit'] }\end{array}$ & cf. Bamum nyinyi ${ }^{S}{ }^{\prime}$ 'God' \\
\hline e plur. pron. 'we' & cf. Bamum wap ${ }^{\prime}$ plur. pron. \\
\hline$\bigodot \quad$ [bere 'belly'] & 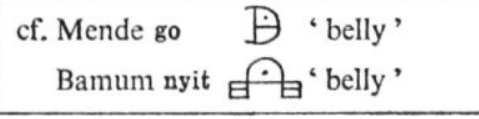 \\
\hline $\mathrm{pa} / \mathrm{pa} \circlearrowleft$ 'pot, pan' & \\
\hline $\begin{array}{l}\text { tu } \text { 'two' } \\
\text { fo } \amalg \text { 'four' }\end{array}$ & cf. Bamum paa 马ु 'two' \\
\hline 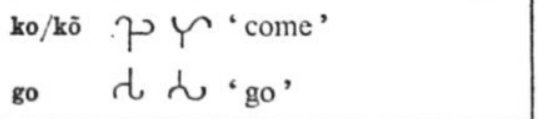 & $\begin{array}{cl}\text { cf. Bamum wuon } & \mathcal{C} \text { 'go' } \\
\text { Vai taa } & \text { F 'go' }\end{array}$ \\
\hline $\begin{aligned} & \text { gi } \text { ' give' (representing } \\
& \text { outstretched hands ?) }\end{aligned}$ & cf. Bamum fa $\$$ ' give \\
\hline nya/nyã $\gamma$ 'eat' & $\begin{array}{ll}\text { cf. Vai don } & \oint \text { ' eat' } \\
\text { Bamum yux } & \oint \text { 'eat, }\end{array}$ \\
\hline pu $\mathscr{f} \gamma^{x}$ [pun'take'] & 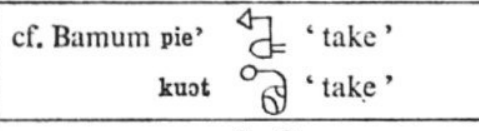 \\
\hline ea $\phi$ 'carry' & cf. Bamum kiem ' 8 'carry' \\
\hline $\begin{array}{c}\text { ne/nẽ }+\begin{array}{c}\text { 'name' (representing } \\
\text { illiterate's mark?) }\end{array} \\
\end{array}$ & \\
\hline $\begin{array}{ccc}\mathrm{mu} / \mathrm{mu} \quad & \bigcirc \quad \text { moon' (i.e. full moon } \\
\text { and crescent moon } \\
\text { combined ?) }\end{array}$ & $\underset{\text { nzun mut }}{\text { cf. Bamum }}$ 'full moon' \\
\hline wa $\lesseqgtr\{$ [watra “water'] & cf. Vai, etc., above (Table IV) \\
\hline $\begin{array}{l}\text { sa } 9 \text { [ [sani 'thing'] } \\
\text { 'Halley's comet' }\end{array}$ & cf. Vai fe 19 [fen 'thing'] \\
\hline
\end{tabular}

Fig. 3. Mogelijke pictogrammen en ideogrammen in het Djoeka-schrift, volgens DALBY, 1968, p. 193, Table VI. 
wij zijn van mening dat deze rotstekeningen in geen geval schrift in de eigenlijke betekenis zijn en hoogst waarschijnlijk ook geen pictografisch of ideografisch schrift. Op deze kwestie hopen wij later in te kunnen gaan in een publicatie over Surinaamse rotstekeningen vergeleken met de andere Zuidamerikaanse en de Caraïbische rotsinscripties, in het bijzonder die van Guyana en Cayenne. Dat dit 'corpus' invloed uitgeoefend heeft op het Afakaschrift is zeer onwaarschijnlijk: niet alleen is er geen enkele overeenkomst aan te wijzen in de vorm, zelfs geen stijlovereenkomst, maar ook is het zo goed als zeker dat AFAKA van die tekens niets anders onder ogen heeft gehad dan enkele vage lijnen op 'Popikiston' bij Godo-Holo aan de boven-Tapanahonie en de twee of drie tekens die met moeite nog te zien zijn op de rots van Bigiston, beneden-Marowijne.

In DALBY's artikel is bladz. I92 geheel aan het Afakaschrift gewijd; op de volgende pagina staat de hier overgenomen Tabel (Fig. 3) met mogelijke pictogrammen en ideogrammen in het Afakaschrift. Het grote belang van het Afakaschrift voor de studie der autochtone Westafrikaanse schriftsoorten volgt uit het feit dat rechtstreeks contact tussen Djoeka's en WestAfrikanen de laatste I5o jaar niet plaats vond, zodat elke overeenkomst van ideografische of pictografische elementen wijst op een gemeenschappelijke erfenis op het gebied van grafische symbolen. De bosnegers hebben, door hun geïsoleerde positie, een cultuur behouden die bijna zuiver Westafrikaans is ${ }^{1}$; daarentegen hebben zij hun Afrikaanse taal verloren ${ }^{2}$, zeker wat de woordvoorraad betreft, die gecreoliseerd Europees is. De Djoekataal is daarom niet zo rijk aan monosyllabische CV-stamwoorden als het Westafrikaans, zodat er minder gevallen zijn dat een syllabeteken samenvalt met een woord. DALBY sluit echter ook

1) Zie echter Wirtschaft und materielle Kultur der Buschneger Surinames door Peter Neumann (Abh. Ber. Mus. Völkerk. Dresden 26, 1967, p. 109) die een heel ander standpunt inneemt.

$\left.{ }^{2}\right)$ Prof. Wils merkt hierover op: "Er was geen gemeenschappelijke taal waarop de Djuka-negers zouden kunnen teruggrijpen. Ze kwamen wel van de z.g. Slavenkust, maar dat is zulk een gemengd gebied en daar zijn zoveel variaties, dat deze mededeling in de grond weinig of niets inhoudt. Het wonder is juist, dat deze slaven, om allerlei gronden bijeengedreven, zich a.h.w. zelf een taal gevormd hebben. Vanzelf werd de woordenschat dus gecreoliseerd Europees, althans niet Afrikaans. Naar mijn mening is het enige dat overblijft een biologicum, nl. de accentvorm, die in beginsel tonaal is". 
tweelettergrepige woorden in, waarvan de beginlettergreep correspondeert met de klankwaarde van een Afakateken (bijv. wa van watra).

De Tabel (Fig. 3) geeft I9 mogelijke verklaringen van Afakatekens, welke verklaringen voor een deel gesteund worden door overeenkomsten met het Vai, Mende of Bamum. Van deze I9 gevallen komen er 5 overeen met de verklaring genoemd in DuBELAAR \& GoNGGRYP, I968 (p. 254). Hun verklaring voor oe(koe) neemt DALBY niet over; hij denkt bij dit teken aan de eerste lettergreep van oema (vrouw) op grond van (vage) vormovereenkomst met een houtsnijmotief dat KAHN aan vaN PANHUYS ontleent en 'symbolized woman' noemt (zie MoRTON C. KAHN: Djuka. The Bush Negroes of Dutch Guiana, I93I, p. 213, fig. 27). Deze verklaringen zijn niet alle overtuigend. Zo wordt het teken voor moe (n) genoemd: "full moon and crescent moon combined?", terwijl AFAKa blijkens de uiterst nauwkeurige copieën van Pater Morssink (zie GongGryp \& DubelaAR: 'De geschriften van Afaka in zijn Djoekaschrift', N.W.I.G. 42, 1963, p. 218-252) nergens de cirkelvorm ('full moon') als basis voor dit teken neemt, maar overal een soort ovaal met puntige uiteinden. Het Afakateken voor wa dat DALBY verklaart als watra doet niet denken aan de golflijn die volgens Tabel IV van zijn artikel in het Vai, Bambara en Bozo water voorstelt. Juju, dat 'spirit' zou betekenen, kennen wij niet, wel jèjè, dat met andere tekens geschreven wordt. Nemen is teki, niet puu (poeroe), dat wegnemen, terugtrekken, uittrekken enz. betekent. 'Halley's comet' is bij AFAKA geen pictogram maar een illustratie, want het is geen deel van de tekst; als men de tekening weglaat blijft de tekst ongeschonden. Het teken voor $p a$ ziet DALBY als een pictogram i.v.m. een pan; de toelichting zou dan echter patoe moeten luiden. Overigens zouden wij, op even losse gronden, eerder aan $p a=$ vader denken, als we letten op de overeenkomst in grondvorm met $m a=$ moeder , dat DALBY als man verklaart. Het gevaar voor "hineininterpretieren" is hier natuurlijk groot.

Daar Dalby zich deze gevaren zeer goed bewust was, poneert hij zijn verklaringen dan ook uiterst voorzichtig als mogelijkheden. Hij schrijft in zijn eerste artikel (I967, p. I7) terecht: "The investigation of possible pictograms and ideograms is a hazardous operation, the imagination of the investigator not necessary being in line with that of the original inventor".

Het is nauwelijks nodig te zeggen, dat deze detailkritiek niets 
afdoet aan onze grote bewondering voor het werk van DAviD DALBY, die doorgedrongen is tot het wezen van de autochtone Afrikaanse schriftsoorten en die daardoor mét de Afrikanistiek ook de Surinamistiek een grote dienst bewezen heeft. Het aangekondigde derde artikel van zijn hand over dit onderwerp zien wij daarom vol verwachting tegemoet. ${ }^{1}$ )

1 Nadat deze bespreking was geschreven verscheen van DALBY in dezelfde serie "Further indigenous scripts of West Africa: Manding, Wolof and Fula alphabets and Yoruba 'Holy' writing." (Afr. Language Studies X, I969, p. I6I-I8I). 